\title{
PHƯƠNG PHÁP XÁC ĐỊNH KHU VỰC RỦI RO LŨ BÙN ĐÁ DỰA VÀO BẢN ĐỒ ĐỊA HİNH
}

\author{
Vũ Bá Thao', Nguyễn Trung Kiên²
}

Tóm tắt: Trong các loại hình thiên tai thường xuyên xảy ra ở miền núi phía Bắc Việt Nam, lũ bùn đá là loại hình thiên tai gây thiệt hại lớn nhất về người và tài sản. Sự xuất hiện của lũ bùn đá thương bất ngò̀, nhanh, khó dụ báo, cảnh báo và rất khó phòng tránh, đa phần gây ra hậu quả hết súc nặng nề. Trong các giải pháp phòng, tránh, giảm thiểu rủi ro lũ bùn đá gây ra, công tác xác định các khu vưc có rủi ro cao, để tù đó có nhũng phuơng án úng phó phù hợp theo cấp độ, cuñng nhu đề xuất các phưong án quy hoạch, xây dưng, phát triển kinh tếxã họi bền vũng là hết sức cần thiết. Nghiên cưu này trình bày một phương pháp đơn giản để xác định các khu vực có rủi ro lũ bùn đá dựa trên bản đồ địa hình, kết hợp với phần mềm Google Earth. Phuơng pháp được áp dụng cho hai khu vưc suối lũ bùn đá tại tỉnh Yên Bái. Kết quả cho thấy vị trí và phạm vi khu vục rủi ro lũ bùn đá - hình rẻ quạt trầm tích trùng khớp với nơi mà nhà cửa và co sở ha tầng bị phá hủy do lũ bùn đá. Kết quả thu được có thể sủ dụng làm cơ sở để xây dưng phuơng án ứng phó khi lũ bùn đá xảy ra cũng nhu đề xuất các quy định tưong ứng với múc độ rủi ro thiên tai.

Từ khóa: Bản đồ địa hình, Google earth, Lũ bùn đá, Rẻ quạt trầm tích, Rủi ro thiên tai.

Ban Biên tập nhận bài: 13/04/2020 Ngày phản biện xong: 18/05/2020 Ngày đăng bài: 25/05/2020

\section{Giới thiệu chung}

Trong cách loại hình thiên tai, lũ bùn đá (LBĐ) là một dạng thiên tai xảy ra phổ biến ở các sông suối miền núi phía Bắc Việt Nam [13]. Lũ bùn đá mang theo nhiều bùn, cát, sỏi, đá, di chuyển với tốc độ lớn, xói mòn hình thái sông, suối và tác động nặng nề đến các khu vực mà nó tràn qua trên cả phương diện con người lẫn kinh tế, xã hội. Sự xuất hiện của lũ bùn đá thường bất ngờ, nhanh, khó dự báo, cảnh báo và rất khó phòng tránh, đa phần gây ra hậu quả hết sức nặng nề [4-5]. Trong các giải pháp phòng, tránh, giảm thiểu rủi ro lũ bùn đá gây ra, công tác xác định các khu vực có rủi ro cao, để từ đó có những phương án ứng phó phù hợp theo cấp độ, cũng như đề xuất các phương án quy hoạch, xây dựng, phát triển kinh tế xã hội bền vững là hết sức cần thiết. Đây cũng là nhiệm vụ mà nhiều quốc gia trên thế giới khi triển khai các phương án phòng

${ }^{1}$ Viện Thủy công, Viện Khoa hoc Thủy lợi Việt Nam

${ }^{2}$ Khoa Xây dụng Dân dụng và Công nghiệp, Đại hoc Xây Dựng

Email:vubathao@gmail.com, kiennt3@nuce.edu.vn tránh lũ bùn đá luôn đặt lên hàng đầu, để từ đó có quy hoạch và sử dụng đất hợp lý [6-11]. Việc xác định cácbản đồ từ đó xác định khu vực có rủi ro cao, chịu tác động nếu lũ bùn đá xuất hiện được triển khai ở nhiều cấp độ khác nhau: trên phạm vi rộng và phạm vi cụ thể.

Có nhiều phương pháp khác nhau, từ đơn giản đến phức tạp để xây dựng các bản đồ cảnh báo, bản đồ phân vùng thảm họa, từ đó xác định các khu vực có rủi ro cao. Có thể kể đến các phương pháp sử dụng mô hình thông tin địa lý (GIS) hoặc kết hợp giữa bản đồ số độ cao (DEM) để đưa ra các công thức kinh nghiệm dự đoán tác động của dòng bùn đá [8,13-14]. Tại Việt Nam, phương pháp chủ yếu được sử dụng để xây dựng các bản đồ rủi ro lũ quét, sạt lở đất hiện nay là phương pháp chồng các bản đồ thành phần dựa trên trọng số. Tuy nhiên các bản đồ này hầu hết ở tỷ lệ nhỏ, việc sử dụng còn nhiều hạn chế và chưa xẩy dựng được bản đồ phân vùng thảm họa cho khu vực cụ thể. Trong khi đó, tại các nước có nhiều kinh nghiệm ứng phó với lũ bùn đá nói riêng và thiên tai nói chung, bản đồ phân vùng khu vực thảm họa được xây dựng chi tiết đến 


\section{BÀI BÁO KHOA HỌC}

từng khu dân cư và cơ sở hạ tầng có liên quan (hình 1).

Nhằm mục đích đóng góp vào công tác phòng, chống giảm thiểu thiệt hại do lũ bùn đá gây ra bằng việc xác định các khu vực có rủi ro cao, từ đó có giải pháp phù hợp, bài báo này tập trung vào việc nghiên cứu phương pháp xác định khu vực có rủi ro cao dựa trên phân loại vị trí có nguy cơ xảy ra lũ bùn đá trong các khu vực cụ thể. Thông qua phương pháp này, các cảnh báo được chỉ dẫn cho một khu vực hẹp, cụ thể, có thể áp dụng ngay vào trong thực tiê̂n nhằm hỗ trợ địa phương có các phương án bảo vệ dân cư, sơ tán, ứng phó kịp thời. Mặt khác, đó là cơ sở để quy hoạch và phát triển việc sử dụng đất hợp lý, an toàn trước thiên tai.

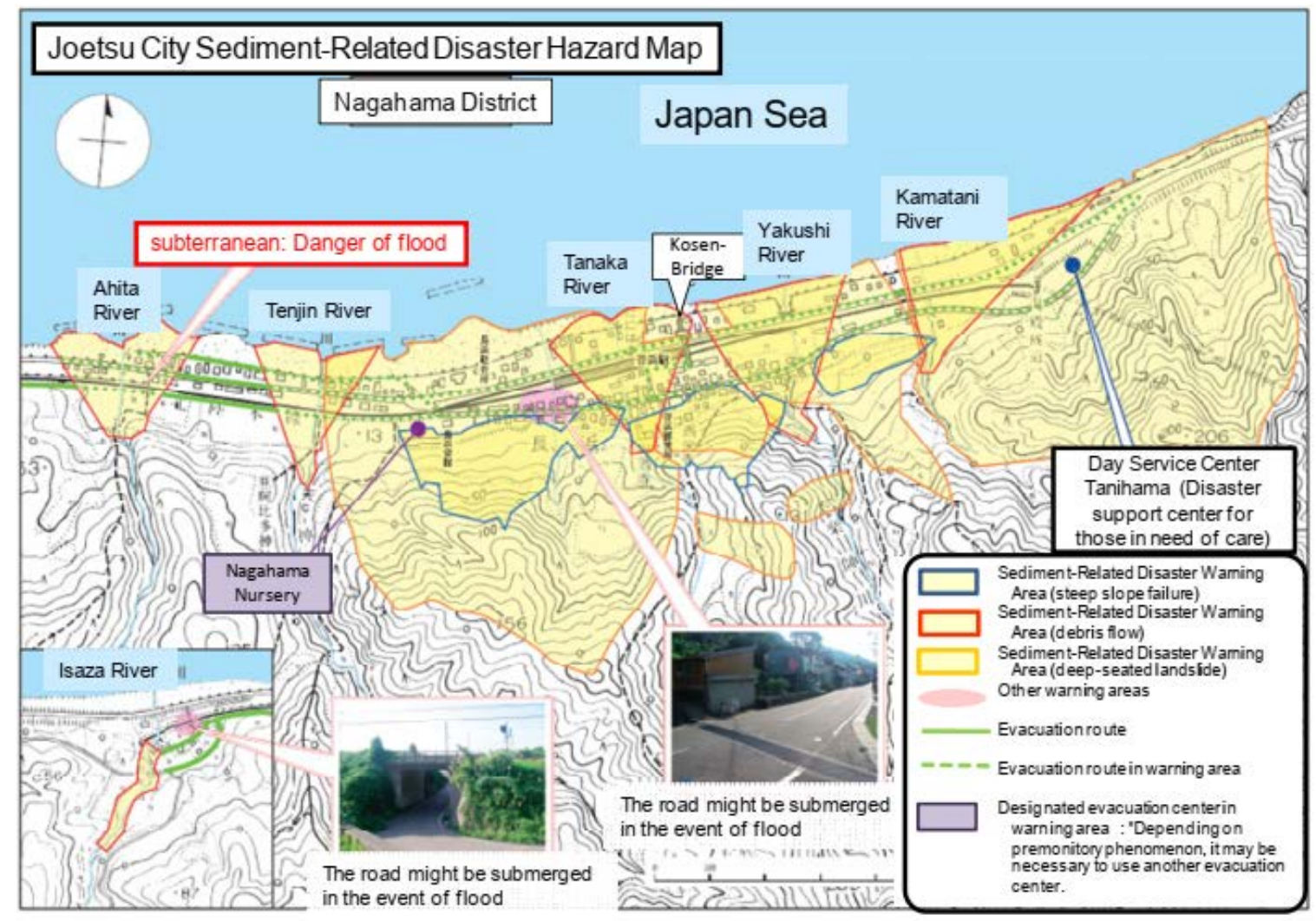

Hình 1. Vỉ dụ một bản đồ phân vùng khu vục thảm họa của Nhật Bản [16], khu vục có khả năng xảy ra lũ bùn đá hoạc sạt lở đất (vùng màu vàng), đường giao thông giúp so tán (đường màu xanh lá), khu vưc đường giao thông dễ bị hu hại (ảnh).

2. Phương pháp nghiên cứu và thu thập tài liệu

2.1 Phuơng pháp xác định khu vục rủi ro do lũ bùn đá

Bài báo trình bày một phương pháp đơn giản, chủ yếu dựa vào bản đồ địa hình để xác định khu vực rủi ro do lũ bùn đá. Tức là xác định khu vực ảnh hưởng của lũ bùn đá nếu lũ bùn đá phát sinh. Khu vực ảnh hưởng hầu hết tại cửa ra của suối/khe/thung lũng. Nội dung xác định khu vực rủi ro do lũ bùn đá là xác định các thông số sau:

(1) Điểm bắt đầu của khu vực rủi ro, còn gọi là hình rẻ quạt trầm tích, hoặc nón phóng vật.
Điểm này gọi là điểm tham chiếu.

(2) Hình dạng hình rẻ quạt trầm tích: là khu vực trầm tích do lũ bùn đá có hình rẻ quạt, điểm bắt đầu gọi là điểm tham chiếu, từ điểm này mở rộng một góc $60^{\circ}$, và dừng lại tại vị trí độ dốc lòng dẫn nhỏ hơn $2^{\circ}$.

(3) Hướng chảy và tác động phá hủy của dòng bùn đá, là hướng thẳng góc với hướng dòng suối, và chỉ đổi hướng khi gặp địa hình hoặc vật cản cao hơn $5 \mathrm{~m}$. Độ cao tác động của hình rẻ quạt trầm tích được xác định là dòng bùn đá không vượt quá chiều cao vật cản cao $5 \mathrm{~m}$.

(4) Lực tác động: Sự dịch chuyển với tốc độ 
lớn của dòng bùn đá tạo nên lực tác động rất lớn, có thể làm đổ nhà bê tông cốt thép, phá hủy cầu, đường v.v... Để xác định được sự chống chịu của các cơ sở hạ tầng này, phải tính toán chi tiết lực tác động dòng bùn đá và khả năng chịu lực của kết cấu.

Phương pháp này cụ thể bao gồm bốn bước như sau:

\section{Bước 1: Xác định điểm tham chiếu hình rẻ quạt trầm tích}

Tại khu vực miền núi, với cùng một độ dốc như nhau, tuy nhiên căn cứ vào độ rộng, hẹp của khu vực, chúng ta có thể phân chia thành các mái dốc thuần túy, thung lũng hẹp hoặc không (hình 2). Kinh nghiệm nghiên cứu của các quốc gia thường xuyên phải đối mặt với rủi ro lũ bùn đá cho thấy, các khu vực chịu ảnh hưởng và tác động do lũ bùn đá gây ra là nơi mà địa hình là các thung lũng dài và hẹp. Vì vậy, điểm đầu tiên trong điều tra, xây dựng phương án giảm thiểu

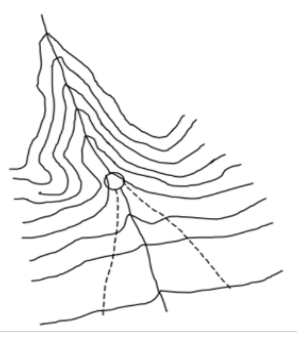

(a) Miệng thung lũng

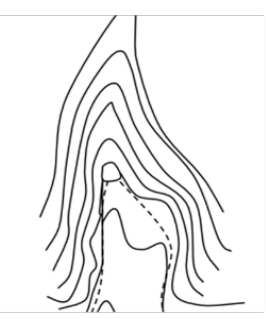

(e) Thung lũng mở rộng

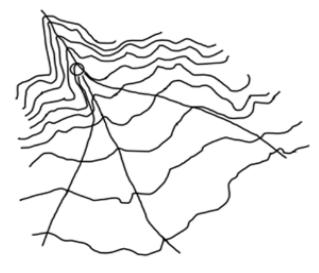

(b) Khu vực lắng

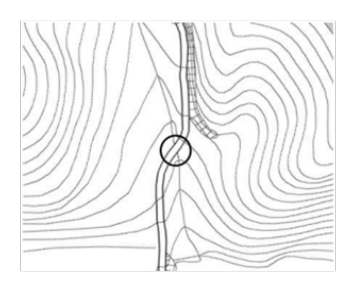

(f) Vị trí kết cấu, công trình rủi ro lũ bùn đá chính là việc cần xác định được các khu vực có rủi ro cao. Như định nghĩa trên hình 2 , các khu vực có rủi ro lũ bùn đá là những địa điểm có độ dốc lớn, nguồn vật liệu đất đá dồi dào, và rủi ro xuất hiện cao tạo nhưng thũng lũng hẹp có chiều rộng nhỏ hơn chiều dài $(\mathrm{a}<\mathrm{b})$.
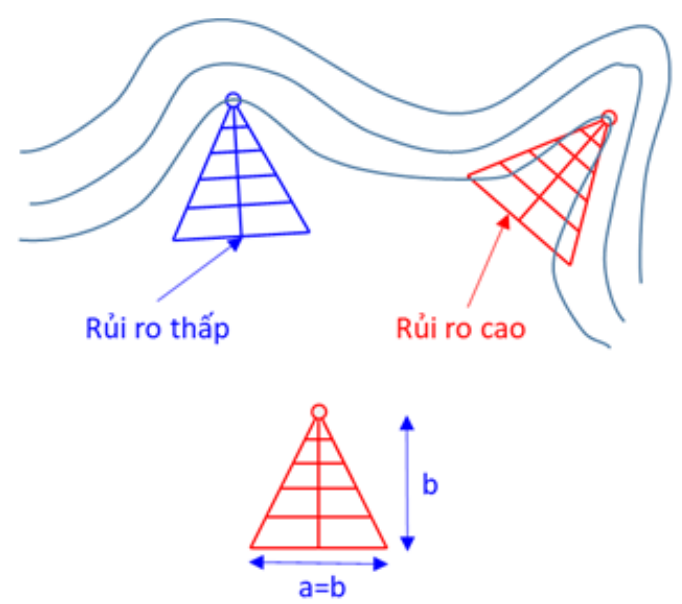

Hình 2. So đồ xác định khu vưc rủi ro lũ bùn đá tì bản đồ địa hình
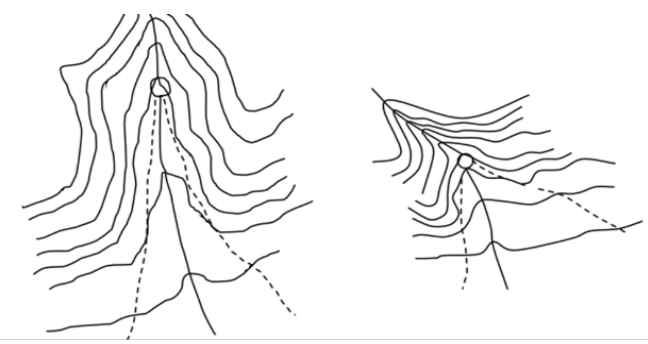

(c) Điểm có sự thay đổi độ dốc

(d) Vị trí suối bị uốn cong

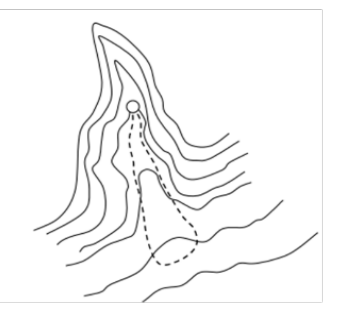

(g) Điểm quan trắc LBĐ

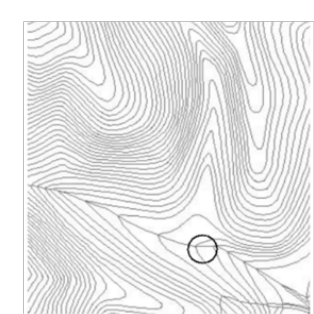

(h) Điểm hợp lưu các suối nhánh

Hình 3. Xác định điểm tham chiếu [12]

Trong công tác điều tra, đánh giá rủi ro do lũ bùn đá gây ra, việc xác định các nguồn sinh lũ, vận chuyển lũ đóng một vai trò quan trọng. Tuy nhiên, một yếu tố quan trọng không kém, đó là cần xác định được điểm mà tại đó dòng lũ bùn đá bắt đầu chuyển sang giai đoạn lắng đọng, trải ra theo hình rẻ quạt $[12,15]$. Trong lập quy hoạch để xây dựng phương án bảo vệ, khu vực bắt đầu từ điểm tham chiếu thông thường là các khu vực có tập trung dân cư sinh sống, đường xá giao thông hoặc ruộng canh tác, hoa màu cần được bảo vệ. Vì vậy việc xác định được điểm tham chiếu có ý nghĩa tiên quyết trong việc tính toán lưu lượng lũ, thiết kế số lượng cũng như kích thước công trình và xây dựng phương án bảo vệ phù hợp.

JICA (2018) [12] phân chia một số cách xác định điểm tham chiếu như minh họa trên hình 3 . 


\section{BÀI BÁO KHOA HỌC}

Tùy vào bản đồ địa hình, khảo sát thực tế, điểm này có thể được xác định ở miệng thung lũng, bắt đầu của vùng lắng, điểm có sự thay đổi lớn về độc dốc, điểm mà suối chuyển hướng dòng, điểm mà thung lũng được mở rộng đột ngột, tại vị trí công trình, cơ sở hạ tầng hoặc điểm giao nhau của nhiều suối nhánh.

\section{Bước 2: Xác định phạm vi hình rẻ quạt trầm tích}

Căn cứ bản đồ địa hình và điểm tham chiếu, xác định lưu vực khu vực cần đánh giá rủi ro lũ bùn đá. Khi lũ bùn đá trải ra trên khu vực lắng, thông qua việc nghiên cứu các trận lũ bùn đá tại
Nhật Bản, ghi nhận góc mở bằng bề rộng thung lũng hoặc khoảng $60^{\circ}$ (hình 4). Giá trị này có thể sử dụng tham khảo tại Việt Nam và điều chỉnh cho phù hợp căn cứ vào các khảo sát, nghiên cứu đầy đủ trongthời gian sắp tới. Một điểm đáng chú ý khác là nghiên cứu cũng ghi nhận tại khu vực này, do động năng dòng bùn đá giảm dần, nó không thể tràn qua một tường chắn có chiều cao lớn hơn $5 \mathrm{~m}$, với giả thiết tường đủ cứng và không bị phá hoại do tương tác với dòng bùn đá. Và dòng bùn đá sẽ dừng lại tại độ dốc nhỏ hơn hoặc bằng $2^{\circ}$.
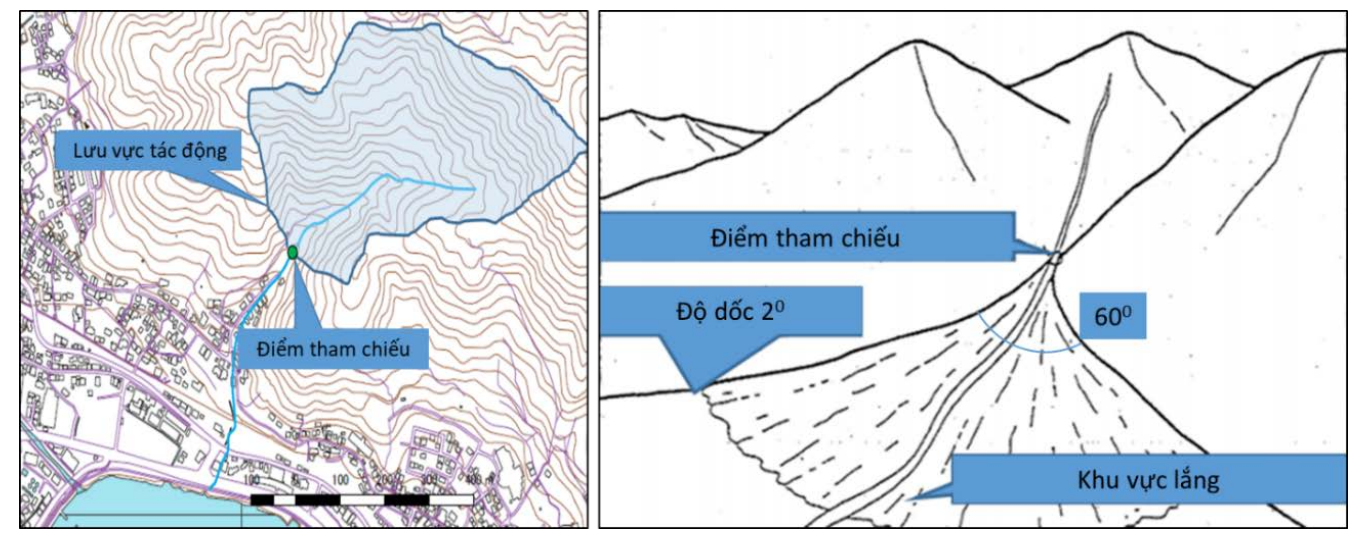

Hình 4. Xác định lưu vục và khu vục lắng [12]

Bước 3: Xác định hướng tác động dòng lũ bùn đá, hướng của hình rẻ quạt trầm tích

Đối với trường hợp xác định cụ thể được hướng dòng chảy (góc mở của các khu vực lắng nhỏ, hẹp) thì hướng tác động của dòng lũ được xác định theo hướng của thung lũng (hình $5 \mathrm{a}$ ). Trong trường hợp thung lũng có góc mở rộng, khu vực tác động của dòng bùn đá thì xác định

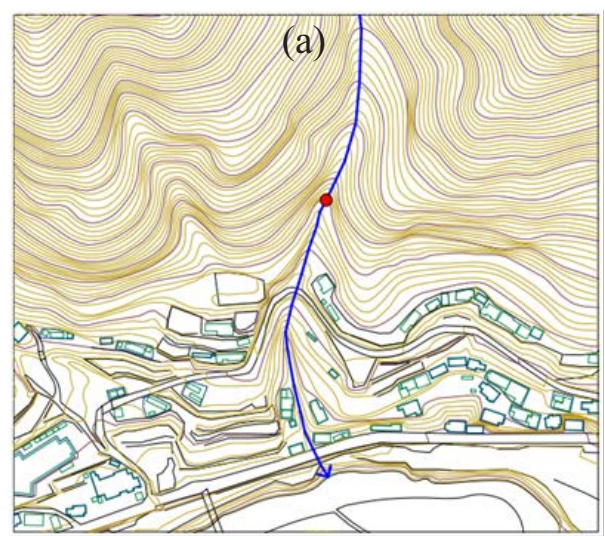

theo các khu vực có địa hình thấp hơn ở xung quanh, và hướng tác động chính căn cứ vào hướng dòng chảy, với góc mở của khu vực lắng tính từ điểm tham chiếu vào khoảng $60^{\circ}$ (hình $5 b)$. Khoảng cách từ điểm tham chiếu đến điểm xa nhất của vùng lắng vào khoảng $200 \mathrm{~m}$ (đối với các vùng lắng có độ dốc trung bình $2^{\circ}$ ).

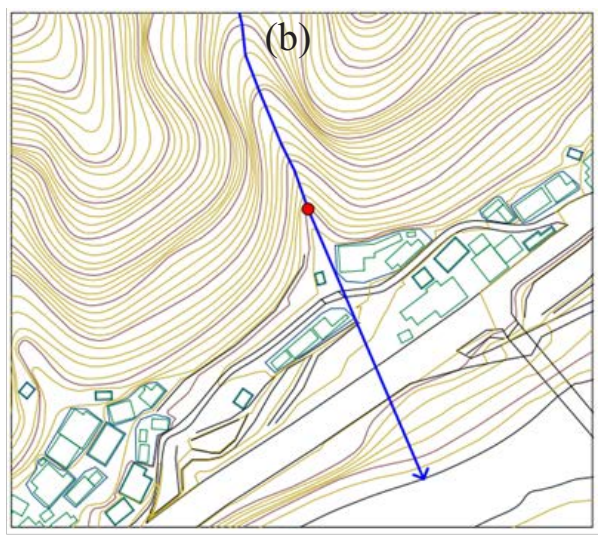

Hình 5. Hương tác động của dòng bùn đá [12] 


\section{Bước 4: Xác định phạm vi phá hủy của dòng bùn đá}

Sau khi đã xác định được nguồn gốc sinh lũ, khu vực tác động cũng như tính toán được lực tác động của dòng lũ $(\mathrm{F})$, so sánh giá trị này với khả năng chịu lực của công trình $(\mathrm{P})$, từ đó làm căn cứ đề xuất các khu vực nguy hiểm cao (không được phép xây dựng công trình - màu đỏ $\mathrm{F}>\mathrm{P}$ ), khu vực nguy hiểm trung bình (xây dựng các công trình ít quan trọng - màu vàng $\mathrm{F}<\mathrm{P}$ ) và khu vực an toàn (bảo đảm an toàn tính mạng người dân và công trình quan trọng - nằm ngoài khu vực màu đỏ và vàng) được miêu tả trên hình 6. Để thực hiện được bước 4 , cần phải có số liệu quan trắc hoặc thí nghiệm xác định lực tác động của dòng bùn đá. Hiện nay tại Việt Nam chưa có nghiên cứu nào về lĩnh vực này. Nghiên cứu cũng chưa có số liệu để phân tích bước 4 nên trong khuôn khổ bài báo chỉ trình bày áp dụng từ bước 1 đến bước 3 .

2.2 Áp dụng phương pháp xác định khu vục rủi ro lũ đá tại Mù Cang Chải và Trạm Tấu

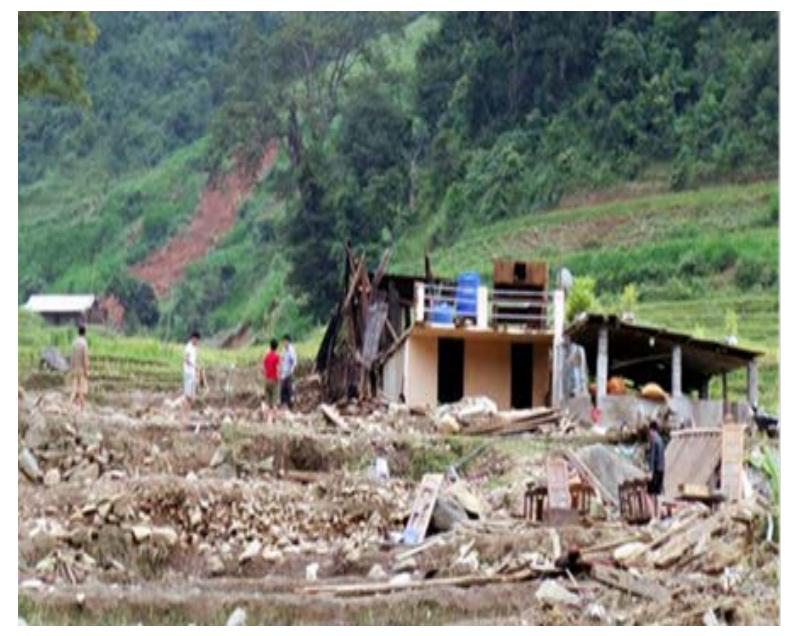

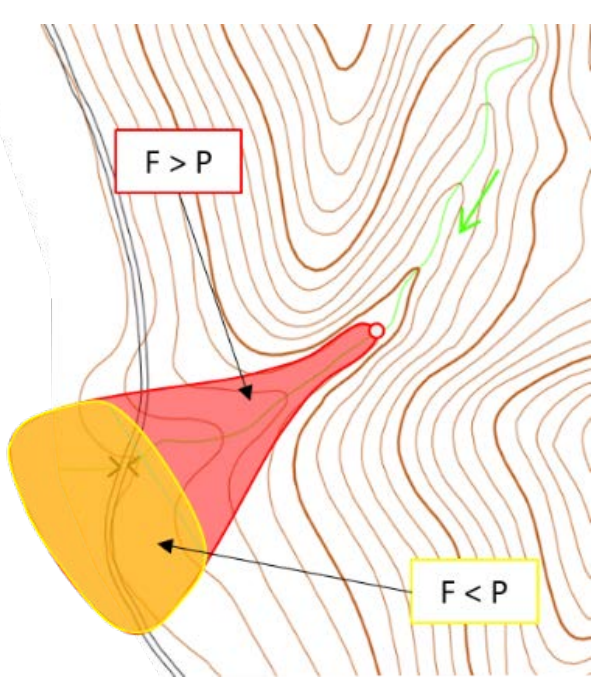

Hình 6. Xác định các khu vục có rủi ro cao

Nhằm thể hiện tính thực tiễn của phương pháp xác định khu vực chịu tác động của lũ bùn đá bằng bản đồ địa hình, trong phần này, bài báo phân tích nguyên nhân, xác định khu vực rủi ro lũ bùn đá cho hai vị trí cụ thể là lũ bùn đá tại xã Hát Lừu, Trạm Tấu, Yên Bái, và lũ bùn đá tại suối Háng Chú, thị trấn Mù Cang Chải, Yên Bái.

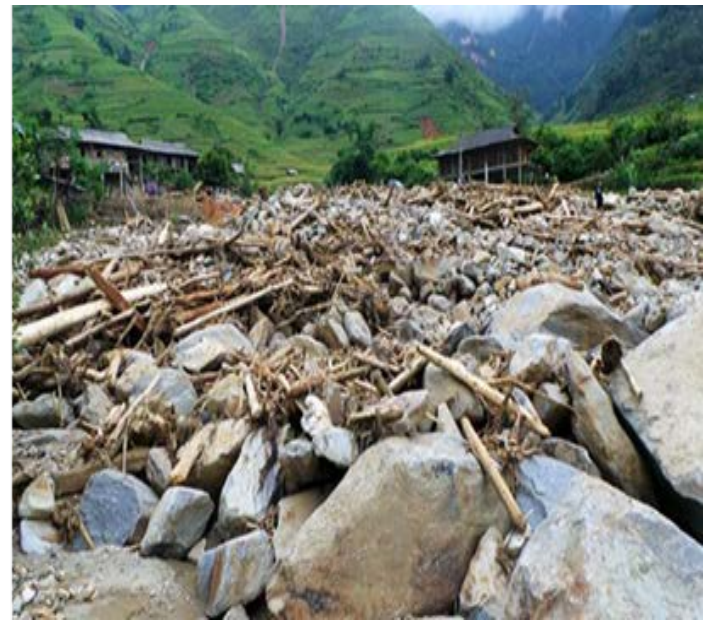

Hình 7. Lũ bùn đá tại xã Hát Lìu, huyện Trạm Tấu năm 2017 [17]

2.2.1 Đặc điểm lũ bùn đá tại xã Hát Lìu, Trạm Tấu, Yên Bái

Huyện Trạm Tấu nằm ở Tây Nam tỉnh Yên Bái, địa hình phần lớn là núi cao với độ dốc trung bình phổ biến từ $30-50^{\circ}$, được cấu thành bởi những thành tạo phun trào núi lửa. Tại địa phương, do nhu cầu phát triển, hiện tượng xẻ núi làm đường, tạo mặt bằng xây dựng nhà cửa, hạ tầng rất phổ biến, kết hợp với sự thay đổi thảm phủ do quá trình canh tác... đã khiến cho các dạng tai biến địa chất có xu hướng gia tăng trên địa bàn [2]. Đặc biệt trong năm 2017, do ảnh hưởng của hoàn lưu cơn bão số 2 gây ra vào ngày 16-17/7/2017 và hoàn lưu cơn bão số 10 từ ngày 09-12/10/2017 trên địa bàn huyện Trạm Tấu đã có mưa to và rất to, tổng lượng mưa 340 
mm, đặc biệt trong ngày 11/10 lượng mưa 211 mm đã gây ra lũ bùn đá, lũ quét, sạt lở đất diễn ra trên diện rộng, cường độ cao làm thiệt hại rất nặng nề về người, tài sản của Nhà nước và nhân dân trên địa bàn xã làm 08 người chết, sập trôi hoàn toàn 11 nhà, sạt lở phải tháo dỡ, di dời 28 nhà, sập trôi 01 cầu treo dài $35 \mathrm{~m}$ tại thôn Búng Tầu, xã Hát Lừu, 01 cầu bê tông $6 \mathrm{~m}$ tại thôn Hát 2 xã Hát Lừu... gây thiệt hại lớn về tài sản [1]. Một số hình ảnh lũ bùn đá tại cửa ra suối thể hiện trên hình 7.

\subsection{2 Đặc điểm lũ bùn đá tại suối Háng chú thị trấn Mù Cang Chải}

Huyện Mù Cang Chải có cấu trúc địa chất rất phức tạp, các vận động địa chất trong khu vực là điều kiện thích hợp phát sinh tai biện địa chất nói chung và lũ bùn đá nói riêng. Với địa hình dốc và

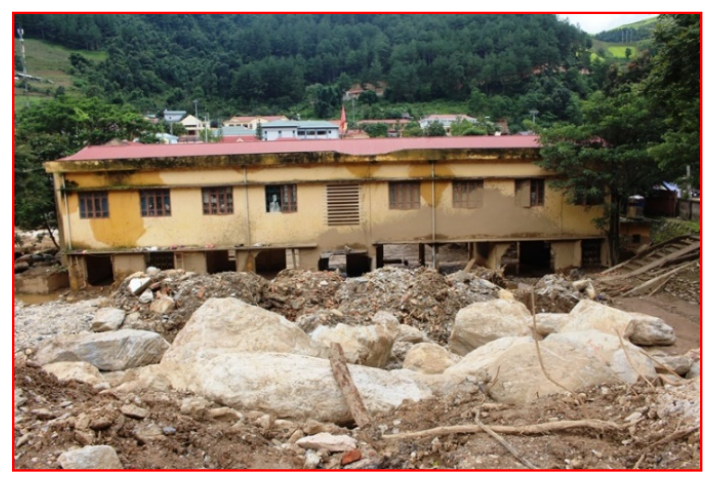

Trường học tại khu vực rẻ quạt trầm tích bị phá hủy

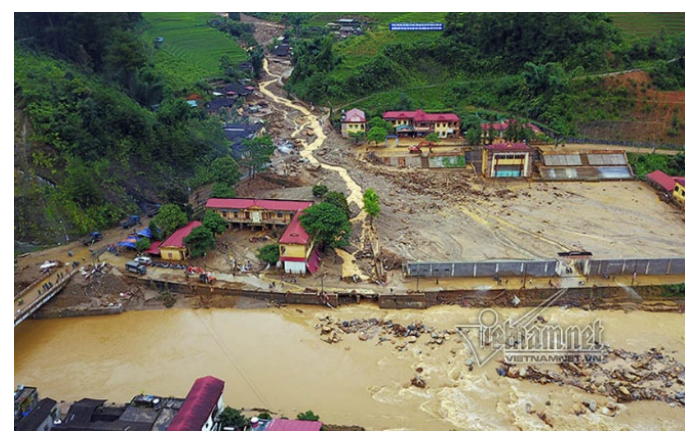

Toàn cảnh khu vực rẻ quạt trầm tích ngay sau lũ cao, chia cắt mạnh, mạnh lưới khe suối cũng như thung lũng hẹp xuất hiện phổ biến, vỏ phong hóa dày... đã khiến cho nơi đây trở thành một điểm nóng về trượt lở, lũ bùn đá tại khu vực miền núi phía Bắc. Trong những tai biến địa chất xảy ra tại địa bàn huyện trong những năm vừa qua, thiên tai lũ bùn đá xảy ra vào rạng sáng ngày 03/8/2017 đã gây thiệt hại nghiêm trọng về người và tài sản. Trong khuôn khổ bài bào này, tác giả sẽ tập trung áp dụng phương pháp xác định khu vực có rủi ro lũ bùn đá như đã trình bày, từ đó phân tích sự phù hợp giữa kết quả thu được và tình hình thực tế. Một số hình ảnh lũ bùn đá tại suối Háng chú ngay sau lũ xảy ra, quân đội đã phải khoan nổ mìn các tảng đá lớn tại khu vực hình rẻ quạt (hình 8).

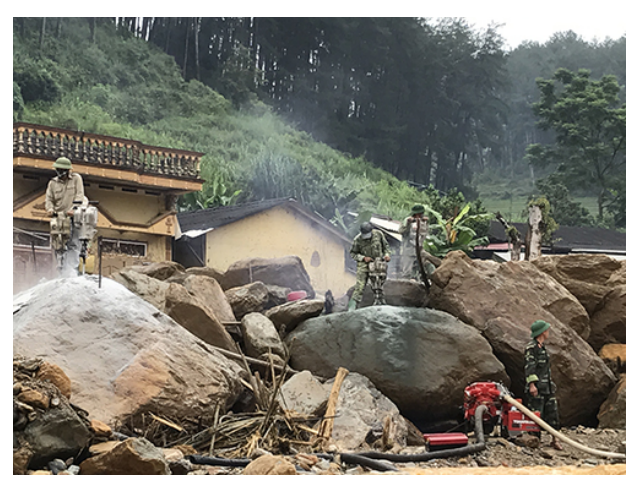

Quân đội phá đá tại khu vực rẻ quạt trầm tích

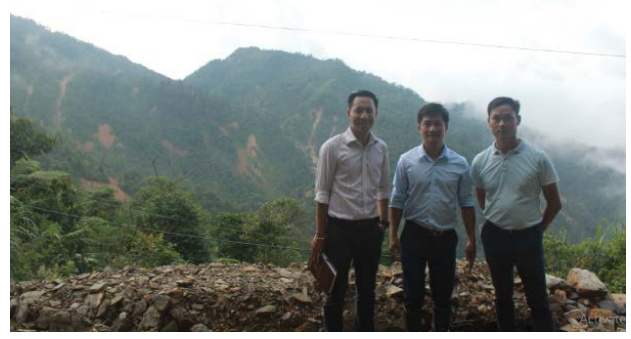

Tác giả khảo sát khu vực sạt trượt - khu vực sinh lũ

Hình 8. Lũ bùn đá tại Mù Cang Chải năm 2017

\section{Kết quả và thảo luận}

\subsection{Xác định vùng rủi ro lũ bùn đá xã Hát}

\section{Lù̀u}

Trong khuôn khổ nghiên cứu này, bài báo lựa chọn khe suối tại vị trí gần UBND xã Hát Lừu để thực hiện phân tích, đánh giá. Đây là khu vực có rủi ro cao lũ bùn đá, có nhiều công trình hạ tầng cần bảo vệ, đặc biệt là trụ sở UBND xã Hát Lừu.
Vị trí địa lý của khu vực nghiên cứu được thể hiện trên hình 9.

Dựa vào bản đồ địa hình nhận thấy khu vực nghiên cứu hội tụ các yếu tố có thể xảy ra lũ bùn đá và là khu vực có nguy cơ chịu tác động cao nếu lũ bùn đá xuất hiện. Sự hình thành, xuất hiện, vận động và tác động của lũ bùn đá tại Trạm Tấu phù hợp với những quy luật chung của dạng thiên 
tai này: được hình thành do mưa lớn dẫn đến sự hình thành đột ngột các hiện tượng trượt nông do sự xuất hiện của dòng chảy mặt. Từ đó đất, đá do sạt lở được tích tụ và vận chuyển theo dòng suối chính. Do độ dốc lớn, địa hình cao, năng lượng của dòng lũ kèm theo bùn đá được gia tăng trong quá trình vận chuyển, gây xói mòn sông suối. Hiện tượng này làm gia tăng thêm hàm lượng chất rắn có trong dòng lũ, tăng mức độ nguy hiểm đối với khu vực chịu tác động.
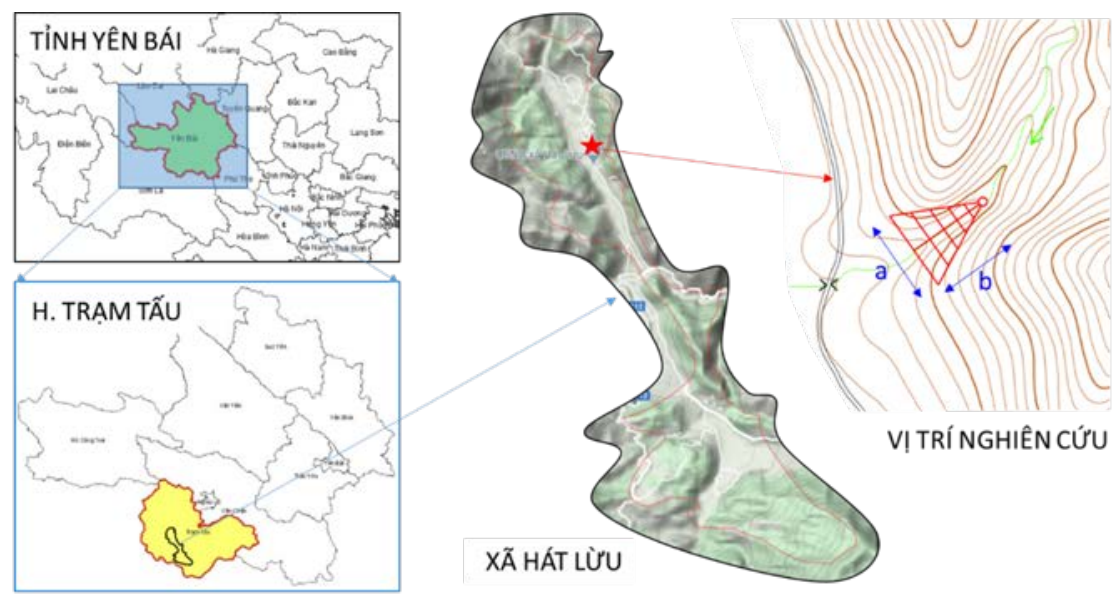

Hình 9. Vị trínghiên cứu

Xác định điểm tham chiếu hình rẻ quạt trầm tich:

Mặt cắt dọc suối được thể hiện trên hình $10 \mathrm{~b}$. So sánh đặc điểm tại vị trí này với các nguyên tắc trình bày trong nội dung 2.1 xác định được điểm tham chiếu tại vị trí mà độ dốc suối thay đổi nhanh, gần miệng thung lũng. Tại khu vực thượng lưu với độ dốc phổ biến trên $30^{\circ}$, hiện tượng trượt lở được ghi nhận, đây là nguồn nguyên liệu dồi dào cho dòng bùn đá trong trường hợp có mưa lớn cục bộ hoặc dài ngày. Tiếp nối của vùng sinh lũ là khu vực vận chuyển có độ dốc khoảng 12-20. Ở cuối giai đoạn vận chuyển, điểm tham chiếu được tìm thấy ở điểm có sự thay đổi đột ngột về độ dốc, gần miệng của thung lũng (hình 9 và hình $10 \mathrm{a}$ ). Từ điểm tham chiếu xác định hướng dòng chảy lũ bùn đá thẳng theo tuyến cửa ra của suối. Mở rộng $60^{\circ}$ và kết thúc ở biên độ dốc lòng dẫn $2^{\circ}$ thì vẽ được phạm vi hình rẻ quạt trầm tích.

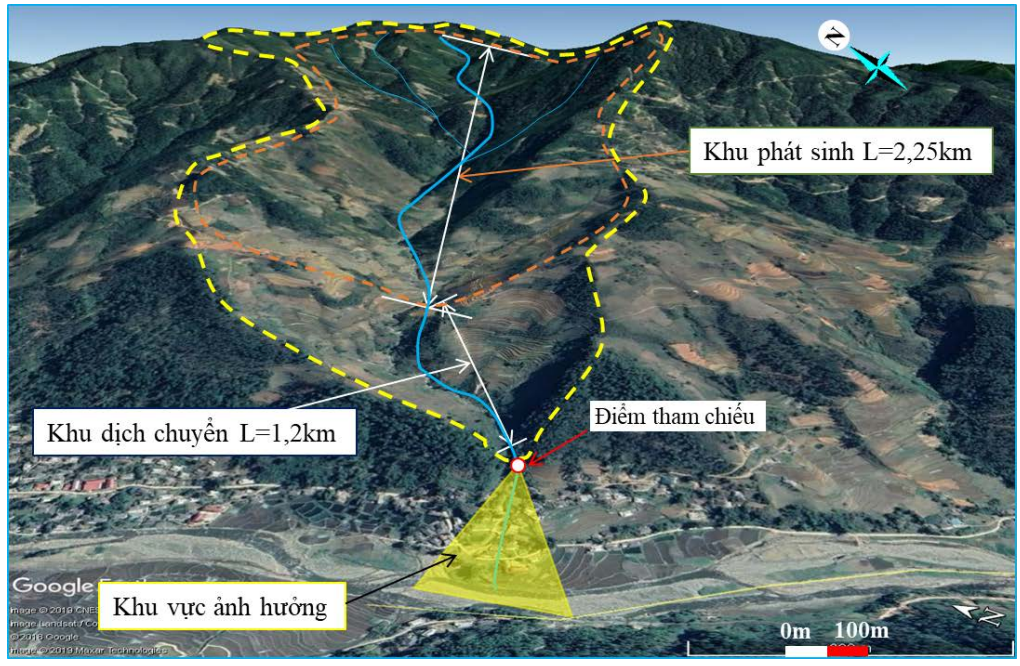

(a)

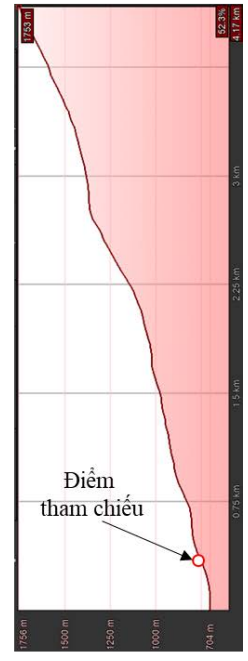

(b)

Hình 10. Xác định phạm vi rủi ro lũ bùn đá tại Hát Lìu: (a) Vị trí và phạm vi rẻ quạt trầm tích; (b) Trắc dọc suối 


\subsection{Xác định khu vục rủi ro lũ bùn đá suối Háng Chú Mù Cang Chải}

Thông qua ba bản đồ Google Earth tại các thời điểm năm 2009, 2015, 2019, và bản đồ chụp UAV năm 2018, khu vực rẻ quạt chịu tác động của dòng bùn đá tại khe Háng Chú được xây dựng như trên hình 11. Từ kết qua thu được chúng ta có thể thấy: (1) Trầm tích (đất, đá, cát, sỏi, gỗ trôi) bắt đầu bồi lắng khi độ dốc lòng dẫn bắt đầu giảm xuống dưới $10^{\circ}$; (2) Hình rẻ quạt mở rộng một góc $60^{\circ}$ và có đường biên giới hạn tại vị trí có độ dốc $2^{\circ}$; (3) Hướng chảy dòng bùn đá: Khi lũ bùn đá quy mô lớn xảy ra hướng chảy của dòng bùn đá đi thẳng trừ khi gặp vật cản cao hơn $5 \mathrm{~m}$. Nếu quy mô lũ chưa đủ lớn, dòng bùn đá vẫn chảy theo hướng dòng suối cũ.

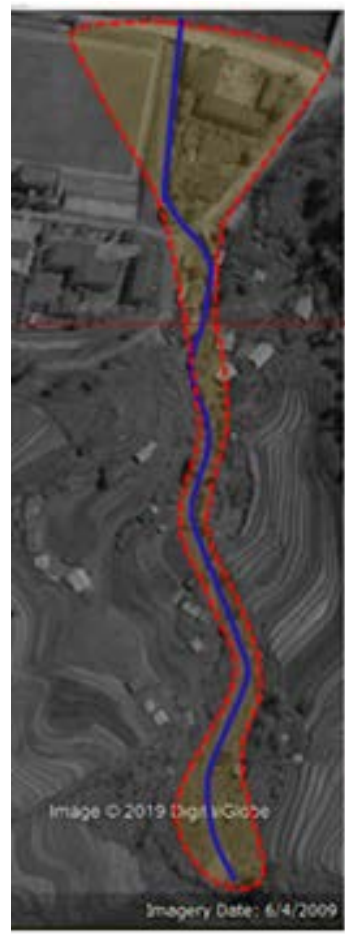

(a)

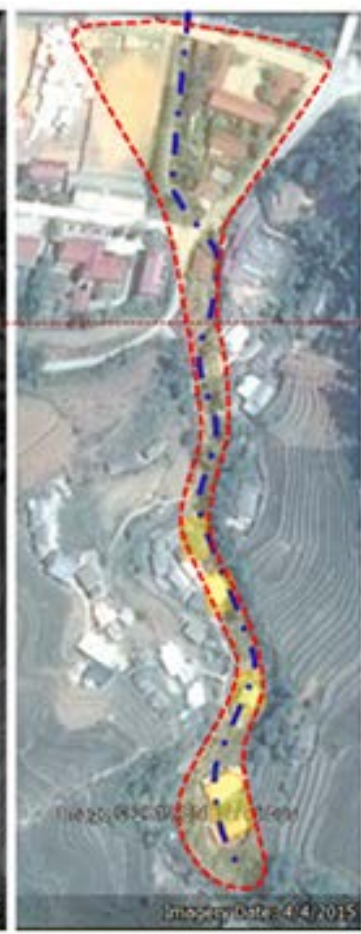

(b)

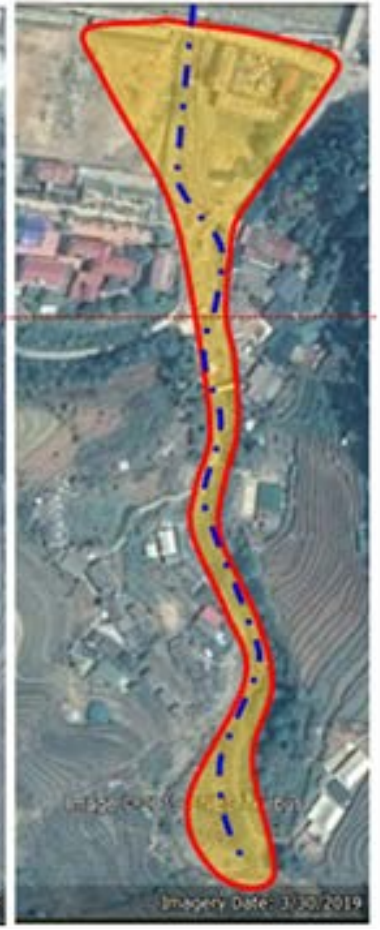

(c)

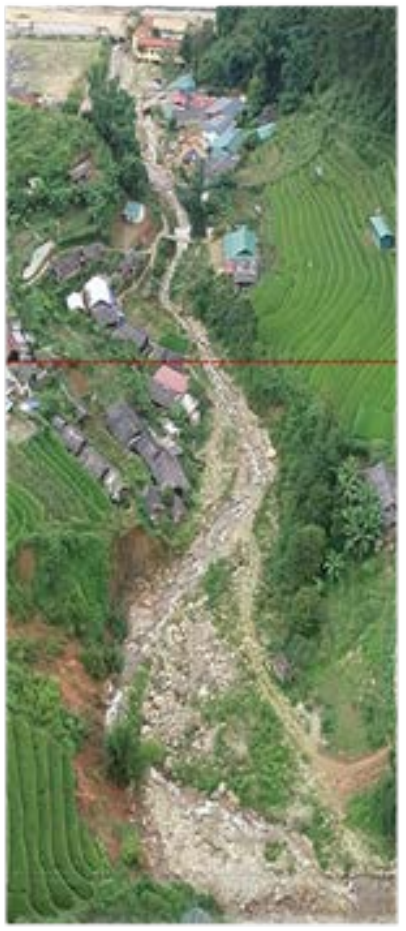

(d)

Hình 11. Phân tích khu vực chịu tác động của dòng bùn đá khe Háng Chú; ảnh chup vệ tinh a) năm 2009, b) năm 2015, c) năm 2019; d) ảnh chup UAV 2018

Hướng chảy dòng bùn đá đi thẳng là phù hợp với thực tế thiên tai tại Mù cang chải. Mặc dù hình thái lòng suối ban đầu (màu xanh nét liền hình 11a) cong, có nhiều đoạn đổi hướng, gẫy khúc, nhưng khi lũ xảy ra, đặc biệt tại đoạn cửa ra rẻ quạt, hướng dòng lũ đi thẳng. Do đó, những ngôi nhà thuộc phạm vi hình rẻ quạt đều bị phá hủy, bao gồm một số ngôi nhà trước cống và trường học. Tại khu vực trầm tích lắng đọng, các ngôi nhà xây dựng sau năm 2009 đều bị phá hủy do đặt nhà gần mép suối, độ nền nhà thấp hơn $5 \mathrm{~m}$ so với đáy suối, các ngôi nhà xây dựng trước năm 2009 không bị phá hủy. Như vậy, nếu trước năm 2009 xây dựng được bàn đồ thảm họa lũ bùn đá để cảnh báo người dân xây nhà thì không bị thiệt hại do lũ năm 2017. Kinh phí người dân bỏ ra để mua đất mới, xây nhà mới và đồ dùng mới sẽ cao hơn nhiều nếu họ xây dựng tại vị trí an toàn trước năm 2017. Điều đó cho thấy, việc xây dựng bản đồ thảm họa lũ bùn đá, sạt lở đất có ý nghĩa lớn về kinh tế và ổn định xã hội. Nếu áp dụng phương pháp xây dựng bản đồ thảm họa lũ bùn đá thông qua xác định khu vực có rủi ro cao như trình bày trong bài báo thì trường học nằm đúng trung tâm hình rẻ quạt, là nơi khu vực cảnh báo đặc biệt mức độ màu đỏ. Lý thuyết này được áp dụng thì sẽ không được xây trường học tại vị trí như hiện nay. Theo cách ứng phó và tái xây dựng sau thiên tai của Nhật Bản, thì mặc dù đã xảy ra lũ bùn đá năm 2017, vẫn có thể xảy ra lũ 
bùn đá tại vị trí này trong tương lai. Vì vậy, cần thiết phải di dời trường học đến một vị trí an toàn hơn, hoặc phải xây dựng đập chắn bùn đá phía trước khu vực rẻ quạt để chắn giữ đất đá, hoặc xây dựng tường bê tông trọng lực kiên cố cao trên $5 \mathrm{~m}$ ngay phía sau trường học. Để bảo vệ an toàn cho các nhà dân, đường giao thông, sân vận động, đoạn kênh hạ lưu nằm giữa sân vận động và trường học, phương án xây đập chắn bùn đá phía trước vị trí điểm tham chiếu trước khi dòng bùn đá bắt đầu chuyển vào khu vực hình rẻ quạt là hợp lý nhất. Tuy vậy, phải thực hiện di dời một số nhà dân để làm đường thi công và phục vụ công tác vận hành.

\section{Kết luận}

Bài báo đã trình bày phương pháp xác định, đánh giá khu vực có rủi ro cao lũ đá trên cơ sở tham khảo kinh nghiệm của Nhật Bản. Đây là một phương pháp đơn giản, dễ áp dụng, có tính định hướng cao và hữu ích trong việc xây dựng phương án ứng phó theo các cấp độ rủi ro thiên tai, đồng thời là tham khảo cho việc quy hoạch sử dụng đất, phát triển kinh tế - xã hội một cách bền vững, chủ động trước thiên tai lũ bùn đá. Dựa trên phương pháp này, bài báo trình bày ví dụ áp dụng cụ thể cho hai địa điểm tại xã Hát Lừu, huyện Trạm Tấu và thị trấn Mù Cang Chải, huyện Mù Cang Chải (tỉnh Yên Bái). Kết quả thu được là minh chứng cho thấy tính khả thi của việc áp dụng phương pháp đối với các khu vực có rủi ro lũ bùn đá tại Việt Nam. Nhóm tác giả kỳ vọng để áp dụng hiệu quả phương pháp này trong thực tiễn tại Việt Nam, đóng góp vào nỗ lực giảm thiểu rủi ro do thiên tai gây ra, đặc biệt là lũ bùn đá, cần thiết có các đề tài, dự án nghiên cứu sâu hơn. Độc giả có thể tham khảo chi tiết hơn về phương pháp trên trong một số tài liệu [9], [18-19].

Lời cám ơn: Nghiên cứu này thuộc đề tài cấp Bộ NN \& PTNT: "Nghiên cứu đề xuất, ứng dụng giải pháp khoa học công nghệ phù hợp trong phòng, chống và giảm thiểu rủi ro lũ quét tại khu vục miền núi phía Bắc", 2019-2021. Nhóm tác giả chân thành cảm ơn sụ hỗ trợ Cơ quan hợp tác quốc tế Nhật Bản (JICA) thông qua khóa đào tạo "Quản lý thiên tai về sạt lở đất và các thiên tai liên quan đến trầm tích".

\section{Tài liệu tham khảo}

1. Ban Chỉ đạo TW về Phòng, chống thiên tai (2017), Tài liệu Thiên tai Việt Nam.

2. Bộ Tài nguyên và Môi trường (2017), Đề án cảnh báo trượt lở.

3. Ngo, T.T.H., Vu, B.T., Nguyen, T.K. (2020), Early warning systems for flash floods and debris flows in Vietnam: A review. In Geotechnics for Sustainable Infrastructure Development, Springer, Singapore, pp. 1233-1240.

4. Nguyễn Trung Kiên, Nguyễn Trần Hiếu, Hoàng Tuấn Nghĩa (2019), Nghiên cúu khả năng áp dụng giải pháp đập hở khung thép ngăn lũ bùn đá tại khu vực miền núi phía Bắc Việt Nam. Tạp Chí Khoa Học Công Nghệ Xây Dựng, 13 (5V), 28-37.

5. Takahashi, T. (1991), Debris flow, IAHR Monograph Series, Rotterdam: Balkema.

6. Chen, C.Y., Lee, W.C., Yu, F.C. (2006), Debris flow hazards and emergency response in Taiwan. WIT Transactions on Ecology and the Environment, 90, pp.10.

7. Huebl, J., Fiebiger, G. (2005), Debris-flow mitigation measures. In Debris-flow hazards and related phenomena Springer, Berlin, Heidelberg, pp. 445-487.

8. Cavalli, M., Crema, S., Trevisani, S., Marchi, L. (2017), GIS tools for preliminary debris-flow assessment at regional scale. Journal of Mountain Science, 14 (12), 2498-2510.

9. Uchida, T., Nishimoto, H., Osanai, N., Shimizu, T. (2009), Countermeasures for sediment-related disasters in Japan using hazard maps. International Journal of Erosion Control Engineering, 2 (2), 46-53.

10. Vu, B.T. (2019), Structural and non-structural countermeasures for prevention and mitiga- 


\section{BÀI BÁO KHOA HỌC}

tion of debris flow disaster. Proceeding of International Conference on Science and Technology for Water Security, Disaster Reduction and Climate Change Adaptation, November 5th, 2019, pp. 431441.

11. Vu, B.T., Nguyen, T.K., Tachi, K. (2019), Proposing preliminary countermeasures against debris flow: case study in nampam commune son la province. Proceeding of International Conference on Science and Technology for Water Security. Disaster Reduction and Climate Change Adaptation, November 5th, 2019, pp. 464-472.

12. Japanese International Cooperation Agency (JICA) 2018\&2019, Lecture documents of Disaster Management for Landslide and Sediment-Related disaster Course, Course number: 201984481-J002.

13. Mori, T., Tanaka, H., Kurihara, J., Mori, K., Tsuzuki, N. (2008), Dissemination of information on debris flow hazard areas using GIS technology. Sabo Frontier Foundation, Tokyo.

14. Zhou, W., Tang, C., Van Asch, T.W., Chang, M. (2016), A rapid method to identify the potential of debris flow development induced by rainfall in the catchments of the Wenchuan earthquake area. Landslides, 13(5), 1243-1259.

15. Osanai, N., (2010), Design standard of control structures against debris flow in Japan. Journal of Disaster Research, 5 (3), 307-314.

16. Uchida, T., Nishimoto, H., Osanai, N., Shimizu, T. (2009), Countermeasures for Sedimentrelated Disasters in Japan using Hazard Maps. International Journal of Erosion Control Engineering, 2 (2), 46-53.

17. Dân trí (2017), https://dantri.com.vn/xa-hoi/lu-san-phang-4-ngoi-nha-suoi-doi-dong-saumot-dem-2017101415304955.htm.

18. Cabinet Office (2018), Flood and Sediment Disaster. Disaster Management Bureau, Sediment disaster hazard zone at page: 4/16.

19. Kunitomo, M. (2003), Applications and Advantages of Hazard Maps for Sabo in Japan. International Training Program on Total Disaster Risk Management, 10-13 June 2003.

\section{TOPOGRAPHIC-MAP-BASED METHOD FOR IDENTIFICATION OF DEBRIS FLOW HIGH-RISK AREAS Vu Ba Thao', Nguyen Trung Kien ${ }^{2}$}

${ }^{1}$ Hydraulic Construction Institute, Vietnam Academy for Water Resources.

${ }^{2}$ Faculty of Building and Industrial Construction, National University of Civil Engineering

Abstract: Debris flow is major types of natural disasters causing great damages to human lives and assets in the northern mountainous provinces. The phenomenon of debris flow is spontaneous, unpredictable and very difficult to avoid, most of which are causing very serious consequences. In the prevention, mitigation and minimization of the risk of debris flow, it is essential to identify highrisk areas from which to have appropriate response plans by level, as well as to propose sustainable socio-economic planning, construction and development plans. This study presents a simple approach, combined with Google Earth tools, to classify areas at risk of debris flow based on topographic maps. This method is then applied to two debris-flow prone areas in Yen Bai province. The results show that locations and areas of disaster risk - alluvial fans, basically concided with places where houses and infrastructures were destroyed by debris flows. The findings can be used as a basis for creating a debris flow response plan, as well as implementing legislation that suit the level of disaster risk.

Keywords: Topographic map, Google earth, Debris flow, Alluvial fan, Disaster risk 